\title{
Clinical and genetic spectrum in 33 Egyptian families with suspected primary ciliary
}

dyskinesia

\section{Running title: Clinical genetic spectrum of Egyptian PCD}

Mahmoud R. Fassad ${ }^{1,2}$, Walaa I. Shoman ${ }^{3}$, Heba Morsy², Mitali P. Patel ${ }^{1}$, Nesrine Radwan ${ }^{4}$, Lucy Jenkins ${ }^{5}$, Thomas Cullup ${ }^{5}$, Eman Fouda ${ }^{4}$, Hannah M. Mitchison ${ }^{1 \#}$, Nader Fasseeh ${ }^{3 \#}$

${ }^{1}$ Genetics and Genomic Medicine Department, University College London, UCL Great Ormond Street Institute of Child Health, London WC1N 1EH, UK

${ }^{2}$ Department of Human Genetics, Medical Research Institute, Alexandria University, 165 ElHorreya Avenue, El-Hadara 21561, Alexandria, Egypt

${ }^{3}$ Department of Pediatrics, Faculty of Medicine, Alexandria University Children's Hospital, Egypt

${ }^{4}$ Department of Pediatrics, Faculty of Medicine, Ain Shams University, Cairo, Egypt

${ }^{5}$ Regional Molecular Genetics Laboratory, Great Ormond Street Hospital for Children NHS Foundation Trust, Queen Square, London WC1N 3BH, UK

\# Joint corresponding authors with equal contribution.

\section{Correspondence:}

${ }^{\#}$ Prof. Hannah Mitchison, PhD

PUW32, GGM

UCL Great Ormond Street Institute of Child Health,

30 Guilford Street, London WC1N 1EH

Tel. +44 (0)20 7905 2866; Email. h.mitchison@ucl.ac.uk

$\&$

"Prof. Nader Fasseeh, MD

Department of Pediatrics, Faculty of Medicine, Alexandria University Children's Hospital

Port Said Street, El Shatby, Alexandria, Egypt 21526

Tel. +2 (0) 1223115079; E-mail: nfasseeh@hotmail.com

This article has been accepted for publication and undergone full peer review but has not been through the copyediting, typesetting, pagination and proofreading process which may lead to differences between this version and the Version of Record. Please cite this article as doi: $10.1111 /$ cge.13661 


\section{Acknowledgements}

We are very grateful to the families who participated in this study. The authors participate in the COST Action BEATPCD: Better Evidence to Advance Therapeutic options for PCD network (BM1407). M.R.F. is supported by the British Council Newton-Mosharafa Fund and the Ministry of Higher Education in Egypt. H.M. is supported by a Daniel Turnberg Travel Fellowship. Other funding for this study was provided by Action Medical Research (GN2101; H.M.M.) and Great Ormond Street Children’s Charity grant (V4515; H.M.M.) and Leadership awards (V1299, V2217; H.M.M.). We acknowledge support from the NIHR Biomedical Research Centre at Great Ormond Street Hospital for Children NHS Foundation Trust and University College London. The views expressed in this publication are those of the authors and not necessarily those of the NHS, the National Institute of Health Research, or the Department of Health.

\section{Conflict of interest statement}

The authors declare no conflicts of interest. 


\section{Data Availability Statement}

The supporting data are available upon request. 


\begin{abstract}
Primary ciliary dyskinesia (PCD) is a rare genetic disorder of motile cilia dysfunction generally inherited as an autosomal recessive disease. Genetic testing is increasingly considered an early step in the PCD diagnostic workflow.
\end{abstract}

We used targeted panel next generation sequencing (NGS) for genetic screening of 33 Egyptian families with highly clinically suspected PCD. All variants prioritized were Sanger confirmed in the affected individuals and correctly segregated within the family.

Targeted NGS yielded a high diagnostic output (70\%) with bi-allelic mutations identified in known PCD genes. Mutations were identified in 13 genes overall, with CCDC40 and CCDC39 the most frequently mutated genes among Egyptian patients. Most identified mutations were predicted null effect variants (79\%) and not reported before (85\%).

This study reveals that the genetic landscape of PCD among Egyptians is highly heterogeneous, indicating that a targeted NGS approach covering multiple genes will provide a superior diagnostic yield than Sanger sequencing for genetic diagnosis. The high diagnostic output achieved here highlights the potential of placing genetic testing early within the diagnostic workflow for PCD, in particular in developing countries where other diagnostic tests can be less available. 
Keywords: Primary ciliary dyskinesia, Phenotype, Genetics, Egypt

\section{Introduction}

Primary ciliary dyskinesia (PCD, MIM\#244400) is a rare inherited disorder caused by abnormal motility of cilia that is usually associated with ciliary ultrastructural defects. PCD most often manifests early in life with neonatal respiratory distress, and later with chronic respiratory disease leading to defective lung function and bronchiectasis. Affected individuals present with a range of nonspecific manifestations including chronic wet cough, rhinosinusitis, otitis media and hearing impairment. About $50 \%$ of patients have laterality problems ${ }^{1}$. Infertility is frequently present in affected adult males ${ }^{2}$.

PCD is primarily an autosomal and X-linked recessive disease. It has high allelic and locus heterogeneity with mutations in over 40 genes known, so far, to lead to PCD (Table S1) ${ }^{3-5}$. These genes encode proteins that are either essential for the multiciliogenesis pathway or are structural and assembly proteins (cytoplasmic dynein assembly factors) of the motor machinery of the ciliary axoneme ${ }^{6}$. 
In the current study, we have used targeted next generation sequencing (NGS) for the genetic investigation of PCD in a cohort of Egyptian families where PCD is highly clinically suspected.

\section{Materials and Methods}

\section{Patients}

The study was ethically approved by the ethics committees at the Faculty of Medicine, Alexandria and Ain Shams Universities and the London Bloomsbury Research Ethics Committee (08/H0713/82). Forty-four patients from 33 unrelated Egyptian families were recruited based on a clinical suspicion of PCD. Self-reported consanguinity data were collected at the time of recruitment. Informed consent was obtained from all participants or their guardians.

Targeted NGS and Data Analysis

This article is protected by copyright. All rights reserved. 
Targeted NGS panel of 321 genes, including all the known PCD genes and other candidate cilia motility genes was used to screen a proband from each family (Table S1). Sequencing data were processed using an in-house bioinformatics pipeline as previously described ${ }^{3,7}$. A search for large insertion/deletion mutations and copy number variants was separately performed, using ExomeDepth software ${ }^{8}$.

Confirmation of the prioritized variants in the affected individuals and segregation within the available family members was performed using standard Sanger sequencing.

\section{Results}

\section{Clinical characteristics of the affected individuals}

Forty-three participants were below 18 years old (1 month - 18 years) at the time of recruitment, only one affected individual was 33 years old. Parental consanguinity was reported in $73 \%$ of the families. The majority of the participants showed typical PCD clinical symptoms, including a history of neonatal respiratory distress (70\%), chronic wet cough (95\%) and rhinosinusitis (80\%). Chest CT data revealed bronchiectasis and alveolar consolidations in $76 \%$ of the 
examined 33 individuals. Dextrocardia was documented in more than half of the patients (55\%).

(Table 1) The distribution of cardiac situs according to the mutated PCD genes, showed that patients with mutations in PCD genes can have either normal or abnormal cardiac situs. As expected ${ }^{1}$, only normal cardiac situs (levocardia) was reported in patients with mutations in a specific subset of PCD genes including genes encoding central complex components (HYDIN), radial spokes components (RSPH9, RSPH4A, DNAJB13) and genes essential for multiciliogenesis (CCNO) (Figure 1A, 1B).

\section{Genetic landscape of PCD among Egyptian patients}

Bi-allelic variants in 13 autosomal recessive genes were identified, Sanger-confirmed and correctly segregated in 23 families, representing a high overall genetic diagnostic output of 70\%. In 2 families (14 and 15), only one mutated allele (single heterozygous) was identified in known PCD genes. (Table 1, 2).

The 13 mutated genes are all members of various different functional gene groups implicated in PCD ${ }^{9}$. This therefore reveals a high genetic heterogeneity among PCD patients in Egypt, consistent with the high recorded rate of consanguineous marriage among Egyptians ${ }^{10}$ and within this study cohort (73\%). The CCDC40 gene was the most frequently mutated gene within 
the studied cohort of families. Together, two functionally related 'ruler protein' genes, CCDC40 and CCDC39, ${ }^{11}$ were the most prevalent mutated functional group of genes. Mutations in these genes result in microtubular disorganization and loss of inner dynein arms from the cilia of affected patients.

The next collectively most prevalent mutations were detected in two genes, DNAH5 and DNAI1, encoding outer dynein arm components and associated with outer dynein arm loss. DNAH11 also codes for an outer dynein arm protein, but mutations in this gene are notably associated with normal ciliary ultrastructure when analyzed by transmission electron microscopy (TEM), as widely reported ${ }^{12-14}$.

\section{Egyptian PCD mutation spectrum includes novel and recurrent mutations}

About $79 \%$ of the variants were predicted to be null truncating variants including stop-gain, frameshift, mutations affecting splicing and CNVs. Most of the prioritized variants had a CADD score of more than 20 (Table 2 and Figure 1C). Using ExomeDepth software to search for CNVs, we identified 2 different homozygous deletions in CCDC40 in two unrelated families, 5 and 22 (Table 2, Figure 1D). 
Apart from the p.Gln144* stop-gain variant in RSPH4A, which was found in two unrelated families (one in a homozygous state and the other as a single heterozygous variant), all the other 26 variants were detected once per family. Interestingly, the p.Gln144* variant was reported before as a single heterozygous variant in a patient with a central microtubular complex defect ${ }^{15}$. Three out of the remaining 26 variants were also reported before (Table 2). The inframe deletion p.Lys268del in RSPH9 has been reported several times before in Bedouin families, arising from one of the most common founder mutations in the Arab peninsula ${ }^{16-19}$. The frameshift mutation p.Leu176Alafs*10 in CCDC39 was reported twice before in two unrelated families from Zimbabwe and UK, indicating that this is a more universal allele reported in various ethnicities 11. The stop-gain mutation p.Cys1678* in DNAH5 was also reported before, in an Italian PCD patient ${ }^{20}$, again indicating sharing of alleles with European descent PCD patients. All the other variants identified in the current study have not been previously reported. (Table 2) 


\section{Discussion}

In the current study, we have used the targeted NGS approach for genetic screening of a cohort of Egyptian patients in order to investigate the genetic landscape of PCD among Egyptians and to evaluate genetic analysis as a diagnostic tool for PCD, with high potential in developing countries that may lack an established clinical service for other specialized techniques required for diagnosis e.g. TEM and high speed video microscopy (HSVM). The benefit of investing in genetic testing extends beyond its diagnostic value, to the appropriate genetic counselling of other family members as well as the affected individuals.

To the best of our knowledge, this is the first report to investigate the genetic background of PCD in Egypt, despite the paucity of clinical reports of Egyptian patients with $\mathrm{PCD}^{21}$. A high genetic diagnostic output was obtained (70\%). This was equivalent between patients with and without situs inversus and without any prior TEM, HSVM or nitric oxide screening; however, this cohort largely display severe respiratory symptoms suggestive for PCD. This yield is comparable to the output of other studies, where causative mutations could be identified in 70-

$80 \%$ of PCD patients. ${ }^{22-25}$. Genetic testing has therefore proved to be a highly successful single test for PCD diagnosis in Egypt. 
A 70\% diagnostic success also indicates that there still remain new variants and likely also new genes to be identified to cause PCD in Egyptian populations. In two families, only a single heterozygous variant was found in affected individuals, highlighting the difficulties that can be encountered when targeted sequencing is used for genetic diagnosis of rare diseases. In these cases, a second mutation may be one that is not readily detected by this sequencing approach, such as a deep intronic mutation affecting splicing that has not been included into the NGS sequence capture design ${ }^{26}$.

Despite the genetic heterogeneity revealed in this Egyptian cohort, mutations in genes essential for microtubular organization (CCDC40, CCDC39) were jointly more commonly mutated than DNAH5 (considered to be the overall most commonly mutated gene in PCD ${ }^{27}$ ) and DNAI1 (also reportedly commonly mutated ${ }^{28}$ ), which both encode outer dynein arm proteins. This frequency of mutations in the two 'ruler protein' genes may be due to aspects of disease recognition in Egypt, as the more severe phenotypes that are associated with mutations in these genes can more highly warrant clinicians to investigate for PCD ${ }^{14}$. In addition to the Arabic founder mutation RSPH9 p.Lys268del ${ }^{16-19}$, previously reported $C C D C 39^{11}$, DNAH5 ${ }^{20}$ and $R S P H 4 A^{16}$ mutations were detected in Egyptian patients (Table 2), likely in patients of Arabic origin but additional haplotyping could be used to establish the extent of shared ancestry outside Egypt. 
In summary, we have described the use of targeted multi-gene panel sequencing for genetic screening of PCD in Egypt. We showed a high diagnostic yield of about $70 \%$ among patients with highly suggestive PCD diagnosis. This highlight the potential of using NGS based genetic testing for PCD diagnosis in developing countries, as an alternative to other potentially more complex investigations e.g. cilia ultrastructural analysis by transmission electron microscopy. 


\section{References}

1. Best S, Shoemark A, Rubbo B, et al. Risk factors for situs defects and congenital heart disease in primary ciliary dyskinesia. Thorax. 2019;74(2):203-205.

2. Lucas JS, Burgess A, Mitchison HM, et al. Diagnosis and management of primary ciliary dyskinesia. Archives of disease in childhood. 2014;99(9):850-856.

3. Fassad MR, Shoemark A, le Borgne P, et al. C11orf70 Mutations Disrupting the Intraflagellar Transport-Dependent Assembly of Multiple Axonemal Dyneins Cause Primary Ciliary Dyskinesia. American Journal of Human Genetics. 2018;102(5):956-972.

4. Fassad MR, Shoemark A, Legendre M, et al. Mutations in Outer Dynein Arm Heavy Chain DNAH9 Cause Motile Cilia Defects and Situs Inversus. Am J Hum Genet. 2018;103(6):984-994.

5. Bustamante-Marin XM, Yin WN, Sears PR, et al. Lack of GAS2L2 Causes PCD by Impairing Cilia Orientation and Mucociliary Clearance. Am J Hum Genet. 2019;104(2):229-245.

6. Mitchison HM, Valente EM. Motile and non-motile cilia in human pathology: from function to phenotypes. J Pathol. 2017;241(2):294-309.

7. Omoyinmi E, Standing A, Keylock A, et al. Clinical impact of a targeted next-generation sequencing gene panel for autoinflammation and vasculitis. PLoS One. 2017;12(7):e0181874.

8. Plagnol V, Curtis J, Epstein M, et al. A robust model for read count data in exome sequencing experiments and implications for copy number variant calling. Bioinformatics (Oxford, England). 2012;28(21):2747-2754.

9. Horani A, Ferkol TW. Advances in the Genetics of Primary Ciliary Dyskinesia: Clinical Implications. Chest. 2018;154(3):645-652. 
10. Romdhane L, Mezzi N, Hamdi Y, El-Kamah G, Barakat A, Abdelhak S. Consanguinity and Inbreeding in Health and Disease in North African Populations. Annu Rev Genomics Hum Genet. 2019.

11. Antony D, Becker-Heck A, Zariwala MA, et al. Mutations in CCDC39 and CCDC40 are the major cause of primary ciliary dyskinesia with axonemal disorganization and absent inner dynein arms. Hum Mutat. 2013;34(3):462-472.

12. Knowles MR, Leigh MW, Carson JL, et al. Mutations of DNAH11 in patients with primary ciliary dyskinesia with normal ciliary ultrastructure. Thorax. 2012;67(5):433-441.

13. Lucas JS, Adam EC, Goggin PM, et al. Static respiratory cilia associated with mutations in Dnahc11/DNAH11: a mouse model of PCD. Hum Mutat. 2012;33(3):495-503.

14. Irving S, Dixon M, Fassad MR, et al. Primary Ciliary Dyskinesia Due to Microtubular Defects is Associated with Worse Lung Clearance Index. Lung. 2018;196(2):231-238.

15. Kott E, Legendre M, Copin B, et al. Loss-of-function mutations in RSPH1 cause primary ciliary dyskinesia with central-complex and radial-spoke defects. Am J Hum Genet. 2013;93(3):561-570.

16. Castleman VH, Romio L, Chodhari R, et al. Mutations in radial spoke head protein genes RSPH9 and RSPH4A cause primary ciliary dyskinesia with central-microtubular-pair abnormalities. Am J Hum Genet. 2009;84(2):197-209.

17. Alsaadi MM, Gaunt TR, Boustred CR, et al. From a single whole exome read to notions of clinical screening: primary ciliary dyskinesia and RSPH9 p.Lys268del in the Arabian Peninsula. Annals of human genetics. 2012;76(3):211-220. 
18. Reish O, Slatkin M, Chapman-Shimshoni D, et al. Founder mutation(s) in the RSPH9 gene leading to primary ciliary dyskinesia in two inbred Bedouin families. Annals of human genetics. 2010;74(2):117-125.

19. Monies D, Abouelhoda M, Assoum M, et al. Lessons Learned from Large-Scale, First-Tier Clinical Exome Sequencing in a Highly Consanguineous Population. Am J Hum Genet. 2019;105(4):879.

20. Boaretto F, Snijders D, Salvoro C, et al. Diagnosis of Primary Ciliary Dyskinesia by a Targeted Next-Generation Sequencing Panel: Molecular and Clinical Findings in Italian Patients. The Journal of molecular diagnostics : JMD. 2016;18(6):912-922.

21. Blanchon S, Legendre M, Copin B, et al. Delineation of CCDC39/CCDC40 mutation spectrum and associated phenotypes in primary ciliary dyskinesia. J Med Genet. 2012;49(6):410-416.

22. Kim RH, D AH, Cutz E, et al. The role of molecular genetic analysis in the diagnosis of primary ciliary dyskinesia. Annals of the American Thoracic Society. 2014;11(3):351-359.

23. Marshall CR, Scherer SW, Zariwala MA, et al. Whole-Exome Sequencing and Targeted Copy Number Analysis in Primary Ciliary Dyskinesia. G3 (Bethesda, Md). 2015;5(8):1775-1781.

24. Djakow J, Kramna L, Dusatkova L, et al. An effective combination of sanger and next generation sequencing in diagnostics of primary ciliary dyskinesia. Pediatric pulmonology. 2016;51(5):498509.

25. Paff T, Kooi IE, Moutaouakil Y, et al. Diagnostic yield of a targeted gene panel in primary ciliary dyskinesia patients. Hum Mutat. 2018;39(5):653-665.

26. Ellingford JM, Beaman G, Webb K, et al. Whole genome sequencing enables definitive diagnosis of Cystic Fibrosis and Primary Ciliary Dyskinesia. bioRxiv. 2018. 
27. Hornef N, Olbrich H, Horvath J, et al. DNAH5 mutations are a common cause of primary ciliary dyskinesia with outer dynein arm defects. American journal of respiratory and critical care medicine. 2006;174(2):120-126.

28. Zariwala MA, Leigh MW, Ceppa F, et al. Mutations of DNAI1 in primary ciliary dyskinesia: evidence of founder effect in a common mutation. American journal of respiratory and critical care medicine. 2006;174(8):858-866. 


\section{Figure legends}

\section{Figure 1. Clinical phenotype and genetic spectrum of Egyptian PCD cohort}

(A) Respiratory phenotype as assessed by CT Chest showing bronchiectasis in the right lung (left image) and dextrocardia (right image). (B) Number of families and distribution of various PCD symptoms according to the mutated gene. (C) Summary of mutation types amongst the 28 gene variants detected in the 23 bi-allelic variant-diagnosed families. (D) Two homozygous deletions found in CCD40 as displayed in IGV browser. Homozygous deletion spanning exons 11-12 detected in Family 5 (top). Homozygous deletion spanning exons 11-16 detected in Family 24 (bottom). Black arrows indicate deletions in patient samples, compared to controls sequenced in parallel. 


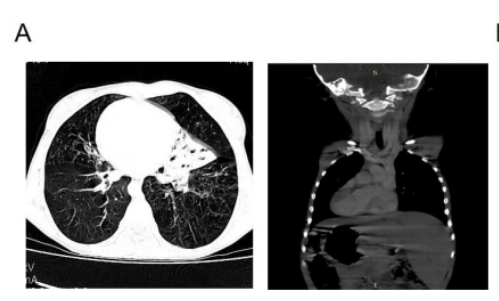

$\begin{array}{lll}- \text { Patients } & \square \text { NRDS } & \square \text { wet cough }\end{array}$ $\mathrm{n}^{\star}$ No. of families with bi-allelic mutations

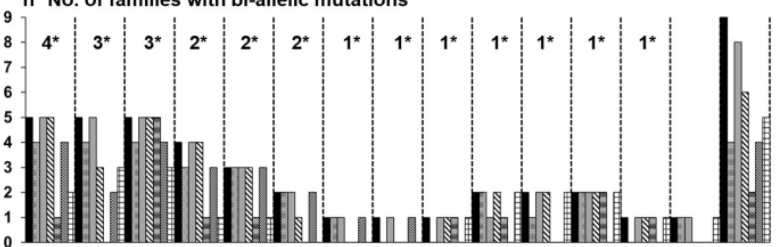

C
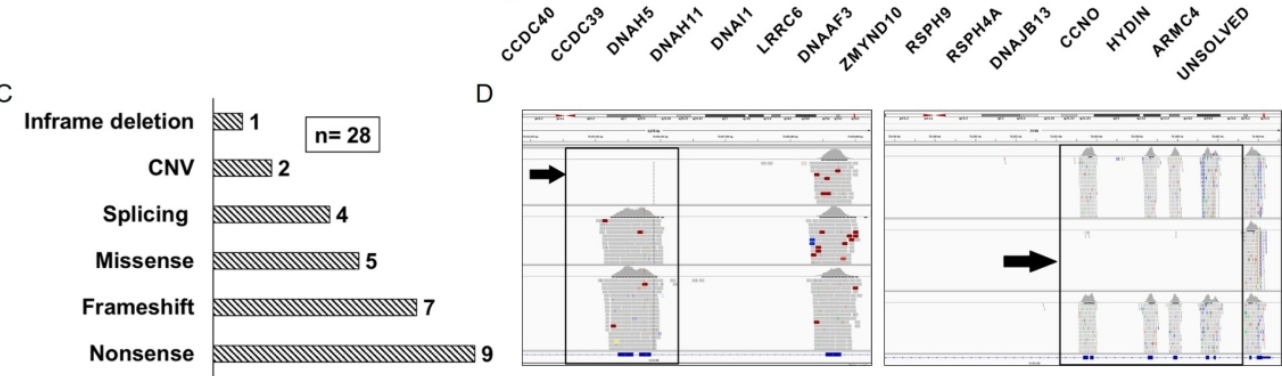
Table 1. Clinical data and summary for the 44 patients from 33 unrelated families enrolled in the study

\begin{tabular}{|c|c|c|c|c|c|c|c|c|c|c|}
\hline $\begin{array}{l}\mathrm{Pa} \\
\text { ID }\end{array}$ & Gender & Consang & NRDS & $\begin{array}{l}\text { Wet } \\
\text { cough }\end{array}$ & $\begin{array}{l}\begin{array}{l}\text { Rhino } \\
\text { sinusitis }\end{array} \\
\end{array}$ & $\begin{array}{l}\text { Otitis } \\
\text { media }\end{array}$ & $\begin{array}{l}\text { Cardiac } \\
\text { situs } \\
\end{array}$ & Chest CT & Gene & Governorate \\
\hline 1 & Male & Yes & Yes & Yes & Yes & No & Dextrocardia & Normal & $C C D C 40$ & Alexandria \\
\hline 2 & Male & Yes & Yes & Yes & Yes & No & Dextrocardia & Normal & - & Alexandria \\
\hline 3 & Female & Yes & Yes & Yes & Yes & Yes & Dextrocardia & Normal & DNAH5 & Alexandria \\
\hline 4 & Female & Yes & Yes & Yes & Yes & No & Dextrocardia & Normal & LRRC6 & Alexandria \\
\hline 5 & Male & Yes & No & Yes & Yes & No & Dextrocardia & Not done & $C C D C 40$ & Beheira \\
\hline 6 & Female & Yes & No & Yes & Yes & Yes & Dextrocardia & Bronchiectasis & \multirow{2}{*}{ DNAH5 } & \multirow{2}{*}{$\underline{\text { Beheira }}$} \\
\hline $6-a$ & Male & Yes & Yes & Yes & Yes & Yes & Dextrocardia & Normal & & \\
\hline 7 & Male & No & Yes & Yes & Yes & Yes & Dextrocardia & Not done & & $\underline{\text { Kafr }}$ \\
\hline $7-\mathrm{a}$ & Female & No & No & Yes & Yes & No & Dextrocardia & Not done & & $\begin{array}{c}\underline{\text { Kafr }} \\
\text { Elsheikh }\end{array}$ \\
\hline 8 & Male & Yes & Yes & Yes & No & No & Levocardia & Atelectasis & \multirow{2}{*}{$C C D C 39$} & \multirow{2}{*}{$\underline{\text { Beheira }}$} \\
\hline $8-a$ & Male & Yes & Yes & Yes & Yes & No & Dextrocardia & Normal & & \\
\hline 9 & Male & No & Yes & Yes & Yes & Yes & Dextrocardia & Normal & $C C D C 40$ & Beheira \\
\hline 10 & Female & Yes & Yes & Yes & Yes & No & Dextrocardia & Not done & \multirow{3}{*}{$D N A H 11$} & $\begin{array}{c}\underline{\text { Kafr }} \\
\text { Elsheikh }\end{array}$ \\
\hline $10-\mathrm{a}$ & Female & Yes & No & Yes & Yes & No & Levocardia & Bronchiectasis & & 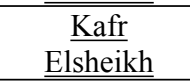 \\
\hline $10-\mathrm{b}$ & Male & Yes & Yes & Yes & Yes & Yes & Dextrocardia & Normal & & 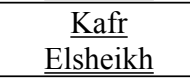 \\
\hline 11 & Female & Yes & Yes & Yes & Yes & No & Dextrocardia & Bronchiectasis & CCDC39 & Alexandria \\
\hline 12 & Female & Yes & No & Yes & No & No & Dextrocardia & Consolidations & ZMYND10 & Alexandria \\
\hline 13 & Male & Yes & Yes & Yes & No & No & Dextrocardia & Not done & $D N A A F 3$ & Cairo \\
\hline 14 & Male & No & Yes & Yes & No & No & Levocardia & Collapse & ARMC4 & Dammietta \\
\hline 15 & Male & Yes & Yes & Yes & Yes & Yes & Levocardia & Gas trapping & RSPH4A & Gharbia \\
\hline 16 & Male & No & No & Yes & Yes & Yes & Levocardia & Bronchiectasis & HYDIN & Sharqia \\
\hline 17 & Female & $\mathrm{No}$ & No & Yes & Yes & Yes & Levocardia & Bronchiectasis & RSPH9 & Sharqia \\
\hline 18 & Male & Yes & Yes & Yes & No & No & Dextrocardia & Not done & LRRC6 & Gharbia \\
\hline 19 & Female & Yes & No & Yes & No & No & Levocardia & Not done & \multirow{2}{*}{$C C D C 39$} & \multirow{2}{*}{ Beheira } \\
\hline 19-a & Female & Yes & Yes & Yes & Yes & No & Levocardia & Bronchiectasis & & \\
\hline 20 & Female & Yes & No & Yes & Yes & Yes & Levocardia & Bronchiectasis & - & Alexandria \\
\hline 21 & Female & No & Yes & Yes & Yes & No & Dextrocardia & Not done & DNAH11 & Alexandria \\
\hline 22 & Female & Yes & Yes & Yes & Yes & No & Levocardia & Bronchiectasis & \multirow{2}{*}{$D N A J B 13$} & \multirow{2}{*}{$\underline{\text { Beheira }}$} \\
\hline $22-\mathrm{a}$ & Female & Yes & No & Yes & Yes & No & Levocardia & Bronchiectasis & & \\
\hline 23 & Female & No & No & Yes & No & No & Levocardia & Bronchiectasis & - & Alexandria \\
\hline 24 & Male & Yes & Yes & Yes & Yes & No & Levocardia & Bronchiectasis & \multirow{2}{*}{$C C D C 40$} & \multirow{2}{*}{$\underline{\text { Alexandria }}$} \\
\hline $24-\mathrm{a}$ & Male & Yes & Yes & Yes & Yes & No & Dextrocardia & Bronchiectasis & & \\
\hline 25 & Male & Yes & Yes & Yes & Yes & No & Dextrocardia & Not done & \multirow{2}{*}{ DNAII } & \multirow{2}{*}{$\underline{\text { Kafr }}$} \\
\hline $25 \mathrm{a}$ & Female & Yes & Yes & Yes & Yes & No & Dextrocardia & Consolidations & & \\
\hline 20 & Male & Yes & Yes & Yes & Yes & Yes & Levocardia & Bronchiectasis & \multirow{2}{*}{ CCNO } & \multirow{2}{*}{$\underline{\text { Kena }}$} \\
\hline $26-\mathrm{a}$ & Male & Yes & Yes & Yes & Yes & Yes & Levocardia & Bronchiectasis & & \\
\hline 27 & Female & Yes & Yes & Yes & Yes & Yes & Dextrocardia & Bronchiectasis & \multirow{2}{*}{ DNAH5 } & \multirow{2}{*}{$\begin{array}{c}\text { Kafr } \\
\text { Elsheikh }\end{array}$} \\
\hline $27-\mathrm{a}$ & Male & Yes & Yes & Yes & Yes & Yes & Levocardia & Bronchiectasis & & \\
\hline 28 & Female & Yes & No & No & No & No & Levocardia & Atelectasis & - & Alexandria \\
\hline 29 & Male & No & Yes & Yes & Yes & Yes & Dextrocardia & Not done & DNAII & Alexandria \\
\hline 30 & Male & Yes & No & Yes & No & No & Dextrocardia & Bronchiectasis & - & Beheira \\
\hline 31 & Female & Yes & Yes & No & Yes & No & Levocardia & Bronchiectasis & RSPH4A & Beheira \\
\hline 32 & Male & Yes & Yes & Yes & Yes & No & Levocardia & Not done & - & Alexandria \\
\hline 33 & Male & No & Yes & Yes & Yes & No & Levocardia & Atelectasis & - & Beheira \\
\hline
\end{tabular}

p proband; -a and -b symbols indicate the siblings of the family's proband; NRDS, neonatal respiratory distress syndrome. PCD gene shown, if mutations were identified comprising bi-allelic variants except in the case of ID 14 and 15, where only single heterozygous variants were identified. 
Table 2. Mutations identified in known PCD genes in the Egyptian patient cohort

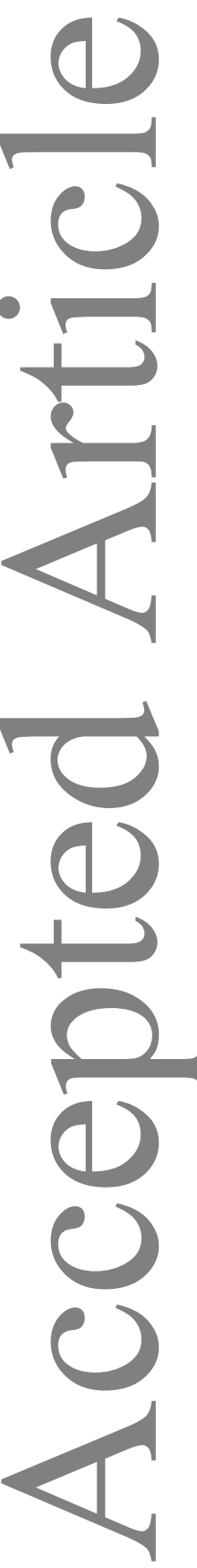

\begin{tabular}{|c|c|c|c|c|c|c|c|c|}
\hline ID & Gene & Zygosity & Impact & c.DNA nomenclature & Protein nomenclature & $\begin{array}{l}\text { gnomAD } \\
\text { MAF }\end{array}$ & $\begin{array}{l}\text { CADD } \\
\text { Score } \\
\end{array}$ & Ref \\
\hline 1 & $C C D C 40$ & Homozygous & Stop-gain & NM_017950.3: c.387C $>$ G & NP_060420.2: p.Tyr129* & Not present & 17.95 & \\
\hline 3 & DNAH5 & Homozygous & Missense & $\mathrm{NM}$ 001369.2: c.8320T $>\mathrm{C}$ & NP 001360.1: p.Trp2774Arg & Not present & 29.8 & \\
\hline 4 & LRRC6 & Homozygous & Splice donor & NM_012472.4: c.974+1G>A & NP 036604.2: p.? & Not present & 25.7 & \\
\hline 5 & $C C D C 40$ & Homozygous & Deletion & CNV (del exons 11-12) & & Not present & & \\
\hline \multirow{2}{*}{6} & \multirow{2}{*}{ DNAH5 } & $\begin{array}{l}\text { Compound } \\
\text { Heterozygous }\end{array}$ & Frameshift & NM_001369.2: c.11258del & NP_001360.1: p.Asn3753Thrfs*5 & Not present & 36 & \\
\hline & & $\begin{array}{l}\text { Compound } \\
\text { Heterozygous }\end{array}$ & Frameshift & NM_001369.2: c.2964_2965del & NP_001360.1: p.Thr990Asnfs*2 & Not present & 27 & \\
\hline 8 & CCDC39 & Homozygous & Stop-gain & NM_181426.1: c.2182C>T & NP_852091.1: p.Gln728* & Not present & 40 & \\
\hline 9 & CCDC40 & Homozygous & Frameshift & $\begin{array}{l}\text { NM_017950.3: } \\
\text { c.2824_2825insCTGT }\end{array}$ & NP_060420.2: p.Arg942Thrfs*57 & 0.00003608 & 35 & \\
\hline 10 & DNAH11 & Homozygous & Frameshift & NM_001277115.1: c.13494_13500del & NP 001264044.1: p.Ser4498Argfs*15 & Not present & 37 & \\
\hline 11 & CCDC39 & Homozygous & Splice donor & NM_181426.1: c. $210+2 \mathrm{~T}>\mathrm{C}$ & NP 852091.1: p.? & Not present & 25.8 & \\
\hline 12 & ZMYND10 & Homozygous & Stop-gain & NM_015896.2: c.490C >T & NP_056980.2: p.Gln164* & 0.000008029 & 24.4 & \\
\hline 13 & DNAAF3 & Homozygous & Stop-gain & NM_001256715.1: c.48G $>$ A & NP 001243644.1: p.Trp16* & Not present & 42 & \\
\hline 14 & $A R M C 4$ & $\begin{array}{l}\text { Single } \\
\text { Heterozygous }\end{array}$ & Missense & NM_018076.2: c.1706G $>A$ & NP_060546.2: p.Arg569Gln & 0.00003585 & 25.1 & \\
\hline 15 & RSPH4A & $\begin{array}{l}\text { Single } \\
\text { Heterozygous }\end{array}$ & Stop-gain & NM_001010892.2: c.430C $>\mathrm{T}$ & NP_001010892.1: p.Gln144* & 0.00001194 & 35 & 15 \\
\hline \multirow{2}{*}{16} & \multirow{2}{*}{ HYDIN } & $\begin{array}{l}\text { Compound } \\
\text { Heterozygous }\end{array}$ & Missense & NM_001270974.2: c.6662G $>A$ & NP_001257903.1: p.Arg2221Gln & Not present & 24.5 & \\
\hline & & $\begin{array}{l}\text { Compound } \\
\text { Heterozygous }\end{array}$ & $\begin{array}{l}\text { Splice } \\
\text { region }\end{array}$ & NM_001270974.2: c.3785+8C >T & NP_001257903.1:p.? & Not present & 12.71 & \\
\hline 17 & RSPH9 & Homozygous & Inframe del & NM_152732.4: c.804_806del & NP_689945.2: p.Lys268del & 0.0000495 & 17.86 & $16-18$ \\
\hline 18 & LRRC6 & Homozygous & Missense & NM_012472.5: c.403G $>A$ & NP 036604.2: p.Val135Met & 0.00005641 & 23.9 & \\
\hline 19 & CCDC39 & Homozygous & Frameshift & NM_181426.1: c.526_527del & NP_852091.1: p.Leu176Alafs*10 & 0.00001616 & 24.7 & 11 \\
\hline 21 & DNAH11 & Homozygous & Stop-gain & NM_001277115.1: c.5845C>T & NP 001264044.1: p.Arg1949* & 0.000007101 & 42 & \\
\hline 22 & DNAJB13 & Homozygous & Frameshift & NM_153614.3: c.623del & NP 705842.2: p.Pro208Glnfs*8 & Not present & 35 & \\
\hline 24 & CCDC40 & Homozygous & Deletion & CNV (Deletion of exons 11-16) & & & & \\
\hline 25 & DNAII & Homozygous & Frameshift & NM_012144.3: c.1644del & NP_036276.1: p.Trp548* & Not present & 35 & \\
\hline 26 & CCNO & Homozygous & Stop-gain & NM_021147.3: c.307C > T & NP_066970.3: p.Gln103* & 0.0000763 & 41 & \\
\hline 27 & DNAH5 & Homozygous & Stop-gain & NM_001369.2: c.5034C $>$ A & NP_001360.1:p.Cys1678* & Not present & 37 & 19 \\
\hline \multirow{2}{*}{29} & \multirow{2}{*}{ DNAII } & $\begin{array}{l}\text { Compound } \\
\text { Heterozygous }\end{array}$ & Missense & NM_012144.3: c.1352T >A & NP_036276.1: p.Phe451Tyr & 0.000003976 & 27.6 & \\
\hline & & $\begin{array}{l}\text { Compound } \\
\text { Heterozygous }\end{array}$ & $\begin{array}{l}\text { Splice } \\
\text { acceptor }\end{array}$ & NM_012144.3: c.1719-1G >A & NP_036276.1:p.? & Not present & 33 & \\
\hline 31 & RSPH4A & Homozygous & Stop-gain & NM 001010892.2: c.430C $>$ T & NP 001010892.1: p.Gln144* & 0.00001194 & 35 & 15 \\
\hline
\end{tabular}

